\title{
Porous alginate/poly( $\varepsilon$-caprolactone) scaffolds: preparation, characterization and in vitro biological activity
}

\author{
CLAUDIO GRANDI $^{1}$, ROSA DI LIDDO ${ }^{1}$, PIERGIORGIO PAGANIN ${ }^{1}$, SILVANO LORA ${ }^{1}$, \\ DANIELE DALZOPPO $^{1}$, GIAMPIETRO FELTRIN ${ }^{2}$, CHIARA GIRAUDO ${ }^{2}$, MARA TOMMASINI ${ }^{1}$, \\ MARIA TERESA CONCONI ${ }^{1}$ and PIER PAOLO PARNIGOTTO ${ }^{1}$ \\ Departments of ${ }^{1}$ Pharmaceutical Sciences and ${ }^{2}$ Medical-Diagnostic Sciences and \\ Special Therapies, University of Padova, Padova, Italy
}

Received September 1, 2010; Accepted October 18, 2010

DOI: $10.3892 / \mathrm{ijmm} .2010 .593$

\begin{abstract}
In bone tissue engineering, scaffolds with controlled porosity are required to allow cell ingrowth, nutrient diffusion and sufficient formation of vascular networks. The physical properties of synthetic scaffolds are known to be dependent on the biomaterial type and its processing technique. In this study, we demonstrate that the separation phase technique is a useful method to process poly $(\varepsilon-$ caprolactone) (PCL) into a desired shape and size. Moreover, using poly(ethylene glycol), sucrose, fructose and $\mathrm{Ca}^{2+}$ alginate as porogen agents, we obtained PCL scaffolds with three-dimensional porous structures characterized by different pore size and geometry. Scanning electron microscopy and porosity analysis indicated that PCL scaffolds prepared with $\mathrm{Ca}^{2+}$ alginate threads resemble the porosity and the homogeneous pore size distribution of native bone. In parallel, MicroCT analysis confirmed the presence of interconnected void spaces suitable to guarantee a biological environment for cellular growth, as demonstrated by a biocompatibility test with MC3T3-E1 murine preosteoblastic cells. In particular, scaffolds prepared with $\mathrm{Ca}^{2+}$ alginate threads increased adhesion and proliferation of MC3T3-E1 cells under basal culture conditions, and upon stimulation with a specific differentiation culture medium they enhanced the early and later differentiated cell functions, including alkaline phosphatase activity and mineralized extracellular matrix production. These results suggest that PCL scaffolds, obtained by separation phase technique and prepared with alginate threads, could be considered as candidates for bone
\end{abstract}

Correspondence to: Dr Rosa Di Liddo, Department of Pharmaceutical Sciences, University of Padova, Via Marzolo 5, I-35131 Padova, Italy

E-mail: rosa.diliddo@unipd.it

Key words: bone regeneration, scaffold porosity, poly( $\varepsilon$-caprolactone), calcium alginate threads, scaffold pore size tissue engineering applications, possessing the required physical and biological properties.

\section{Introduction}

Regenerated bone is proposed in tissue engineering applications for the treatment of many orthopaedic diseases, such as trauma, bone cancer, metabolic diseases and congenital malformations (1-3). Several approaches have been explored, but various experimental and clinical complications have been observed, including the limited availability of bone tissue, donor-site morbidity, and post-operative pain in regards to the use of autografts $(4,5)$, and poor functional outcomes due to the limited vascularization, low cellularity, significant risk of pathogen transmission and immune reactions in the use of allografts (6). Furthermore, some limitations in the use of synthetic grafts are the fibrous encapsulation, the lack of remodelling and the subsequent fatigue-associated graft failure (7). Since the last decade, tissue engineering has provided viable alternatives for harvested tissues, implants and prostheses. As part of the rapid development of biomaterial technologies to repair orthopaedic defects, scaffolds made by biocompatible and bioresorbable polymers and composite materials have been developed for providing temporary support of damaged bone and to sustain tissue regeneration $(8,9)$.

Scaffolds used in tissue engineering applications must have compatible biological and physical properties to match the physiological conditions in vitro and in vivo. Their physical and structural properties, such as interconnectivity, porosity and surface morphology, play a key role in cell adhesion, behaviour and tissue development. Moreover, to be considered appropriate for bone regeneration applications the scaffolds must fulfill basic criteria, including having mechanical properties similar to those of the bone repair site, biocompatibility, biodegradability and osteoconductivity (10-13). The fundamental concepts guiding the development of bone tissue-engineered scaffolds are based on the selected biomaterial and the production method (14). To date, many synthetic polymers have been investigated as scaffolds for bone tissue engineering, including poly(glycolic acid) (PGA), the simplest linear aliphatic polyester; poly(lactic acid) (PLA), 
an $\alpha$-polyester used widely in medical applications; their copolymers, such as poly(lactic-co-glycolic acid) (PLGA); and poly( $\varepsilon$-caprolactone) (PCL) $(13,15,16)$. PGA and PLA are biodegradable and biocompatible; they have a degradation rate ranging from 12 months to over 2 years for PLA, and from 4 to 12 months for PGA. Their mechanical properties are relatively weak for high porosity scaffolds, which limit their usage on the hard tissue regeneration applications (11) Moreover, the breakdown products from scaffold degradation (glycolic acid for PGA and lactic acid for PLA) have been shown to induce cytotoxicity and local inflammatory responses (17), particularly in the case of low vascularization due to slow drainage of waste products from the implant site $(18,19)$.

PCL is a semicrystalline $\alpha$-polyester, approved by the Food and Drug Administration (FDA) for implantation in the human body. It degrades through hydrolytic scission and has resistance to rapid hydrolysis. Because of its biocompatibility properties, degradation rate and mechanical strength, it has been investigated as a biomaterial for medical drug delivery devices (20-25), and load-bearing bone tissue engineering applications $(26,27)$. PCL is characterized by a resorption time slower than other polyesters $(28,29)$, and a negligible weight loss (below $2 \%$ in 30 days) $(30,31)$. After in vivo implantation, its mechanical properties appear to remain unchanged for about 5-6 months (32) and the hydrolytic degradation occurs after about 2 years (33). The slow degradation kinetics result in a reduced risk of acidosis from the rapid accumulation of acidic by-products (20).

A crucial role in bone formation is played by the pore sizes and the interconnectivity of synthetic biomaterials. Suitable pore size guarantees the migration and proliferation of osteoblasts and mesenchymal cells, as well as the diffusion of factors and vascularization (34-36), while the total porosity improves the connection of the implant biomaterial with the surrounding natural bone (37). The pore sizes which better sustain bone mineralization appear to be approximately $100-200 \mu \mathrm{m}$ (38) while the optimal total scaffold porosity is considered to be the one ranging between $80-90 \%$ (39) .

Several different techniques have been established to obtain scaffolds with open pore structures. The most common three-dimensional biodegradable polymer scaffolding fabrication approaches include fiber bonding (40), solvent-casting/ particulate leaching $(41,42)$, gas foaming $(43,44)$, phase separation (45-49) and electrospinning (10,50,51). Almost all techniques allow the production of porous, biodegradable scaffolds, which, however, result do not appear to be suitable for bone regeneration: fiber bonding and gas foaming techniques do not allow for a fine control of porosity, while solvent-casting/particulate leaching is used to produce only thin scaffolds (thickness $\sim 3 \mathrm{~mm}$ ) which lack the mechanical property required for the load-bearing tissue. In contrast, the phase separation technique is characterized by high flexibility and could be appealing for obtaining bone tissue-engineered scaffolds: various parameters can be changed to tailor pore size and porosity and scaffolds with controlled morphology, defined shape and size (52-55).

The aim of the present study was to obtain PCL scaffolds by means of phase separation technique using different porogen agents in order to achieve three-dimensional porous matrices with defined porosity, mechanical properties and microstructure which allow the osteoblastic adhesion, growth and differentiation.

\section{Materials and methods}

Reagents. PCL (MW $\sim 65 \mathrm{kDa}$, density 1.145) was purchased from the Sigma Chemical Company (St. Louis, MO). Sucrose and ethanol were obtained from Carlo Erba Reagenti (Rodano, Italy). MC3T3-E1 mouse embryo/fetus calvaria fibroblast cells were obtained from DSMZ (Braunschweig, Germany), while the $\alpha$-modified minimal essential medium ( $\alpha$-MEM) and gentamicin/amphotericin were from Invitrogen (Grand Island, NY). The CellTiter $96^{\circledR} \mathrm{AQ}_{\text {ueous }}$ Non-Radioactive Cell Proliferation Assay was purchased from Promega (Madison, WI). All other chemicals and reagents were provided by the Sigma Chemical Company.

\section{Preparation of PCL scaffolds by phase separation technique} PCL without porogen (PCL-WP). PCL ( $17.5 \% \mathrm{w} / \mathrm{w})$ was dissolved in tetrahydrofuran (THF) for $2 \mathrm{~h}$ at room temperature under continuous agitation. Distilled water $(50 \%$ of the solution's weight) was then added to the PCL solution under stirring, and two phases (aqueous and gel) were obtained. The aqueous phase was discarded and the obtained gel was transferred into a polyethylene cylindrical mould $(3 \mathrm{~cm}$ diameter, $4 \mathrm{~cm}$ high). The polyethylene moulds containing the gels were incubated at $-30^{\circ} \mathrm{C}$ until complete solidification $(24 \mathrm{~h})$. The solid cast was thrown out from the mould and the solvent THF was removed. The PCL scaffolds were incubated in ethanol three times at $-30^{\circ} \mathrm{C}$ for $24 \mathrm{~h}$, followed by two washes with distilled water. Disk shaped slides of scaffolds were prepared ( $1 \mathrm{~cm}$ diameter, $1 \mathrm{~mm}$ thickness) and stored in water at $4^{\circ} \mathrm{C}$ until use.

Porous PCL scaffolds. Poly(ethylene glycol) (PEG), sucrose, fructose, or calcium alginate were used as porogen agents for the preparation of PCL scaffolds.

PCL-PEG. PEG 1000 was dissolved in THF together with PCL in order to obtain the following three PEG/PCL weight ratios: $15 / 100,30 / 100$ and $100 / 100$. Distilled water $(50 \%$ of the solution's weight) was added to the PCL-PEG solution under stirring, and two phases (an aqueous and a gel phase) were obtained. The gel phase was transferred into a polyethylene cylindrical mould. The samples were incubated at $-30^{\circ} \mathrm{C}$ until complete solidification $(24 \mathrm{~h})$. Subsequently, the solvent and PEG were removed by cold ethanol $\left(-30^{\circ} \mathrm{C}\right)$ and water washings.

PCL-sucrose (PCL-S). Distilled water $(50 \%$ of the solution's weight) was added to the initial PCL solution under stirring, and the aqueous and gel phases were collected. Sucrose particles were milled, sieved and three particle sizes (50-140 $\mu \mathrm{m}, 140-180 \mu \mathrm{m}$ and 180-600 $\mu \mathrm{m}$ ) were selected and added to the PCL gel phase at various weight ratios. The finest sucrose particles (50-140 $\mu \mathrm{m}$ and 140-180 $\mu \mathrm{m})$ were added to PCL in a $15 / 100$ ratio $\left(\mathrm{PCL}-\mathrm{S}_{1}\right)$, while the largest ones $(180-600 \mu \mathrm{m})$ were added in $15 / 100,30 / 100$ and $100 / 100$ ratios $\left(\mathrm{PCL}-\mathrm{S}_{2}\right)$. The gel phase with porogen was transferred into a polyethylene cylindrical mould and incubated at $-30^{\circ} \mathrm{C}$ until complete solidification $(24 \mathrm{~h})$. The solvent and sucrose were then removed as previously described. 
PCL-fructose spheres $(P C L-F)$. Fructose spheres were produced by an emulsion technique (56). Fructose $(20 \mathrm{~g})$ was melted for $90 \mathrm{~min}$ at $120^{\circ} \mathrm{C}$ until complete liquefaction. An emulsion was obtained by adding mineral oil $(20 \mathrm{ml})$ and Span $80(0.52 \mathrm{ml})$ under constant stirring. The resulting mixture was cooled in an ice bath to allow the formation of fructose spheres. After removing the mineral oil, the obtained spheres were washed five times with hexane, heated for 30 min at $37^{\circ} \mathrm{C}$ to compact the spheres and eliminate the hexane, were dried under vacuum and finally sieved selecting the sizes from 150-400 $\mu \mathrm{m}$. The PCL gel was loaded with the fructose spheres using the following fructose/PCL weight ratios: $25 / 100,50 / 100$ and $100 / 100$. The gel was then placed into a mould and incubated at $-30^{\circ} \mathrm{C}$ until complete solidification $(24 \mathrm{~h})$. The solvent and fructose were removed as previously described.

$P C L$-calcium alginate spheres (PCL-AS) and PCL-calcium alginate threads $(P C L-A T)$. Sodium alginate $(0.9 \% \mathrm{w} / \mathrm{v})$ was dissolved in water by constant agitation overnight at room temperature (57). Calcium alginate threads or beads were obtained by dripping the solution of sodium alginate into a $\mathrm{CaCl}_{2}$ solution $(50 \mathrm{mM})$ using a syringe needle of $800 \mu \mathrm{m}$ bore constantly or not immersed into the solution. $\mathrm{Ca}^{2+}$ alginate beads (with alginate/PCL weight ratios of 50/100 and 100/100) or $\mathrm{Ca}^{2+}$ alginate threads [with alginate/PCL $100 / 100$ weight ratio $\left(\mathrm{PCL}-\mathrm{AT}_{1}\right.$ ) or with alginate/PCL 200/100 weight ratio $\left(\mathrm{PCL}-\mathrm{AT}_{2}\right)$ ] were added to the gel phase. The gel was then transferred into the mould and incubated at $-30^{\circ} \mathrm{C}$ until complete solidification $(24 \mathrm{~h})$. The THF solvent was removed by incubating the PCL scaffolds in ethanol for three times at $-30^{\circ} \mathrm{C}$ for $24 \mathrm{~h}$. $\mathrm{Ca}^{2+}$ alginate spheres/threads were dissolved and removed with a sodium phosphate solution (0.1 M, pH 7.0) and then with water.

Scaffold characterization. The absence of THF residual solvent within the scaffolds was verified by analyzing the wash solutions by gas chromatography-mass spectrometry (GC-MS) (Varian 3800 GC and Varian Saturn 2000 ion trap MS). Dioxane was used as an internal standard.

Morphological and pore size analysis was performed using a scanning electron microscope (SEM) (58-60). The samples were lyophilized, frozen in liquid nitrogen, fractured, coated with gold and observed using the Stereoscan-205 S SEM (Cambridge Instruments, Cambridge, MA).

Porosity is conventionally considered the measure of void spaces over the total volume $(61)$. Density and microcomputed tomography (MicroCT) $(2,62)$ methods were used to determine the total porosity of the scaffolds. By the first method, total porosity was calculated applying the following equation:

$$
\Phi=\mathrm{V}_{\mathrm{o}} / \mathrm{V}_{1}
$$

where $\Phi$ is the total porosity, $V_{1}$ is the geometrically measured volume, and $\mathrm{V}_{\mathrm{o}}$ is the difference between $\mathrm{V}_{1}$ and the volume calculated by dividing the scaffold weight by the PCL bulk density.

MicroCT analysis was performed only for the PCL-WP and PCL-AT scaffolds. To preserve the scaffold's morphology all the specimens were cut (height, $1 \mathrm{~cm}$; side, $0.5 \mathrm{~cm}$ ) with a lancet preparing regular surfaces. The upper side of each sample was marked to keep the same orientation during the MicroCT acquisition and compression test. Samples were scanned following standard processing procedure using the SkyScan 1172 high resolution MicroCT (SkyScan, Aartselaar, Belgium). The MicroCT settings used were as follows: voltage $57 \mathrm{kV}$; current $167 \mu \mathrm{A}$; exposition time $242 \mathrm{msec}$; field of view (FOV) 1280 x 1024 pixels; isotropic voxel size $8 \mu \mathrm{m}$. All the samples underwent a $360^{\circ}$ rotation, $0.4^{\circ}$ rotation step and a frame averaging 1 . The raw data acquired were reconstructed using the NRecon software (SkyScan). Axial subsequent images (saved as bitmap format) were reconstructed using a back projection algorithm. The bitmap images were analyzed by the SkyScan MicroCTAnalyzer software: the selected volume of interest (VOI) $(3 \times 1.59 \mathrm{~mm})$ was focused in the centre of each PCL scaffold to avoid artifacts from cutting. All the samples were binarized using the same parameters. Porosity and pore quantitative analysis were obtained based on the structural indices measured for bone samples as reported by Hildebrand et al (63). Sample porosity was calculated as:

$$
\Phi=1-\mathrm{BV} / \mathrm{TV}
$$

where $\Phi$ is the total porosity, BV the bone volume and TV the total volume.

Trabecular thickness (Tb.Th) (or pore wall) and trabecular separation (Tb.Sp) (or pore diameter) were computed by direct measurements. Three-dimensional images were reconstructed by the CTVol software (SkyScan) and by the open source software, Osirix.

PCL-AT scaffolds were subjected to compression testing by the SkyScan Material Testing Stage and were compressed in a continuous mode. The maximum load was $22 \mathrm{~kg}$ with real-time visualization of the displacement curve.

Modelling PCL replicas of a human finger phalanx. A silicon mould of a human finger phalanx was prepared at the Paleontologic Laboratory-Ca' Foscari University of Venice, Italy. To obtain a replica of the phalanx bone, PCL-WP gel was injected into the pre-cooled mould $\left(-20^{\circ} \mathrm{C}\right)$ and then incubated at $-30^{\circ} \mathrm{C}$ until complete solidification $(24 \mathrm{~h})$. Subsequently, the solvent was removed by cold ethanol $\left(-30^{\circ} \mathrm{C}\right)$ and water washings.

MC3T3-E1 cell culture. MC3T3-E1 murine pre-osteoblastic cells were cultured in T75 culture flasks (BD Biosciences, San Jose, CA) with $\alpha$-MEM and $10 \%$ foetal bovine serum (FBS) without antibiotic and were incubated at $37^{\circ} \mathrm{C}$ in a $5 \%$ $\mathrm{CO}_{2}$ humidified atmosphere. Cells from passage 8-12 were used for the experiments. PCL-AT scaffolds were sterilized in $95 \%$ ethanol for $2 \mathrm{~h}$, incubated in PBS solution containing $2 \%$ gentamicin/amphotericin (Invitrogen) for $2 \mathrm{~h}$, and then washed three times of $30 \mathrm{~min}$ each in $\alpha$-MEM. Scaffolds were placed in Millicel culture plate inserts (Millipore, USA), seeded with MC3T3-E1 cells $\left(3 \times 10^{4}\right.$ cells $\left./ \mathrm{cm}^{2}\right)$ and incubated at $37^{\circ} \mathrm{C}$ in a $5 \% \mathrm{CO}_{2}$ humidified atmosphere.

Cell morphology. At different time points ( 24 h, 7 and 14 days), samples were removed from the culture medium, rinsed 
Table I. Different PCL scaffolds obtained using phase inversion technique.

\begin{tabular}{llc}
\hline Scaffold & \multicolumn{1}{c}{ Porogen } & Porogen:PCL (w/w) \\
\hline PCL-WP & None & 0 \\
PCL-P & PEG-1000 & $15: 100 ; 30: 100 ; 100: 100$ \\
PCL-S & Sucrose (range, $50-140$ and 140-180 $\mu \mathrm{m})$ & $15: 100$ \\
PCL-S & Sucrose (range, 180-600 $\mu \mathrm{m})$ & $15: 100 ; 30: 100 ; 100: 100$ \\
PCL-F & Fructose spheres (diameter, 150-400 $\mu \mathrm{m})$ & $25: 100 ; 50: 100 ; 100: 100$ \\
PCL-AS & Calcium alginate spheres (diameter, 1500 $\mu \mathrm{m})$ & $50: 100 ; 100: 100$ \\
PCL-AT & Calcium alginate threads (diameter, $1000-1500 \mu \mathrm{m})$ & $100: 100$ \\
PCL-AT $_{2}$ & Calcium alginate threads (diameter, $1000-1500 \mu \mathrm{m})$ & $200: 100$ \\
\hline
\end{tabular}

with PBS and fixed using glutaraldehyde $(3 \%)$ in sodium cacodylate buffer $(0.1 \mathrm{M}, \mathrm{pH} 7.2)$ for $24 \mathrm{~h}$ at $4^{\circ} \mathrm{C}$. The scaffolds were then washed three times with sodium cacodylate buffer, dehydrated through a graded series of ethanol and air dried. The samples were coated with gold and observed by SEM.

Cell viability. Cell viability was monitored after $24 \mathrm{~h}, 72 \mathrm{~h}$, 7 days and 14 days by the colorimetric MTS assay (3-(4,5dimethylthiazol-2-yl)-5-(3-carboxymethoxyphenyl)-2-(4sulfophenyl)-2H-tetrazolium). Metabolically active cells react with the tetrazolium salt in the MTS reagent to produce a soluble formazan dye that can be detected at $490 \mathrm{~nm}$. At each time point, the cellular constructs were rinsed with PBS, in order to wash out unattached cells, and transferred into another well for a $3 \mathrm{~h}$ incubation with $20 \%$ MTS reagent prepared in culture medium. Thereafter, aliquots were pipetted into 96-well plates and the samples were read at $490 \mathrm{~nm}$ with an ELx808 Ultra microplate reader (BioTek Instruments). A calibration curve (cell number $/ \mathrm{cm}^{2}=2.5 \times 10^{5} \mathrm{~A}^{490}-8.6 \times 10^{4}$, $\mathrm{R}^{2}=0.99$ ) was prepared by carrying out the assay with MC3T3-E1 cells cultured for $4 \mathrm{~h}$.

In vitro biological behaviour of MC3T3E1 cells on porous $P C L-A T$ scaffolds. The cells were seeded $\left(3 \times 10^{5}\right.$ cells $\left./ \mathrm{cm}^{2}\right)$

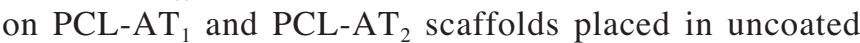
48-well plates (BD Biosciences) containing $600 \mu 1$ culture medium. After $48 \mathrm{~h}$ of seeding, the cells were exposed for $7-21$ days to a medium containing $\alpha$-MEM, $10 \%$ FBS, $1 \%$ APS, $0.1 \mu \mathrm{M}$ dexamethasone, $10 \mathrm{nM}$ B-glycerophosphate and $0.05 \mathrm{mM}$ ascorbate. In parallel, samples were maintained in proliferation medium as a negative control. The differentiation progression of MC3T3-E1 cultured on PCL scaffolds was analyzed as the alkaline phosphatase (ALP) activity, and the extracellular matrix calcium deposition at different timepoints $(7,14,21$ days).

ALP activity was analyzed using p-nitrophenyl phosphate (p-NPP) as a substrate. The cell lysate was centrifuged at $12,000 \mathrm{x} \mathrm{g}$ for $10 \mathrm{~min}$ and the supernatant was incubated with p-NPP at $37^{\circ} \mathrm{C}$ for $30 \mathrm{~min}$. The reaction was terminated by adding $3 \mathrm{~N} \mathrm{NaOH}$ and the absorbance was measured at $405 \mathrm{~nm}$. All results were expressed as mean value $\pm \mathrm{SD}$ of three separate experiments consisting of triplicates.

Mineralized matrix deposition was detected conducting an in vitro mineralization assay using the Osteogenesis Assay kit (ECM810, Millipore). The samples previously fixed with $10 \%$ formalin solution for 15 min were washed twice with distilled water and then incubated with Alizarin Red S for $20 \mathrm{~min}$ at room temperature. After washings with distilled water, and incubation for 30 min with $10 \%$ acetic acid under agitation, cellular monolayers were transferred to microcentrifuge tubes, heated to $85^{\circ} \mathrm{C}$ for $10 \mathrm{~min}$, placed on ice for $5 \mathrm{~min}$ and centrifuged at $20,000 \mathrm{rcf}$ for $15 \mathrm{~min}$. After adding ammonium hydroxide, the amount of extracted Alizarin Red dye was measured at $562 \mathrm{~nm}$ and quantified against an Alizarin Red standard curve. All results were expressed as mean concentration $(\mu \mathrm{M}) \pm \mathrm{SD}$ of three separate experiments performed in triplicate on differentiated and undifferentiated samples.

Statistical analysis. Data are expressed as mean value \pm SD of at least three different samples. Significant differences were estimated by analysis of variance (ANOVA) followed by the Student-Newman-Keuls t-test as a post-hoc test. P-values $<0.05$ were considered significant.

\section{Results}

Scaffold characterization. Table I lists all PCL scaffolds and corresponding porogen agents used. As THF is cytotoxic, its residuals were completely removed from matrices before cell seeding, as demonstrated by the GC-MS profile of the ethanol solution used for the third washing of the samples (Fig. 1).

PCL scaffold characterization and pore size measurements were based on SEM observations while the overall porosity evaluation was performed using the density method and MicroCT.

\section{SEM analysis}

$P C L-W P$. The PCL-WP scaffolds were characterized by a smooth external surface, while SEM analysis of their internal structure showed globular and hallow formations $(20-30 \mu \mathrm{m}$ diameter) with macropores ( $\sim 10 \mu \mathrm{m}$ diameter) (Fig. 2$)$. The estimated total porosity was $70 \%$ and interconnected interstitial voids were detected.

PCL-P. SEM micrographs showed that PCL-PEG scaffolds, prepared with a PEG/PCL weight ratio of $15 / 100$, demonstrated pore sizes ranging from 10 to $50 \mu \mathrm{m}$ (Fig. 3A), 


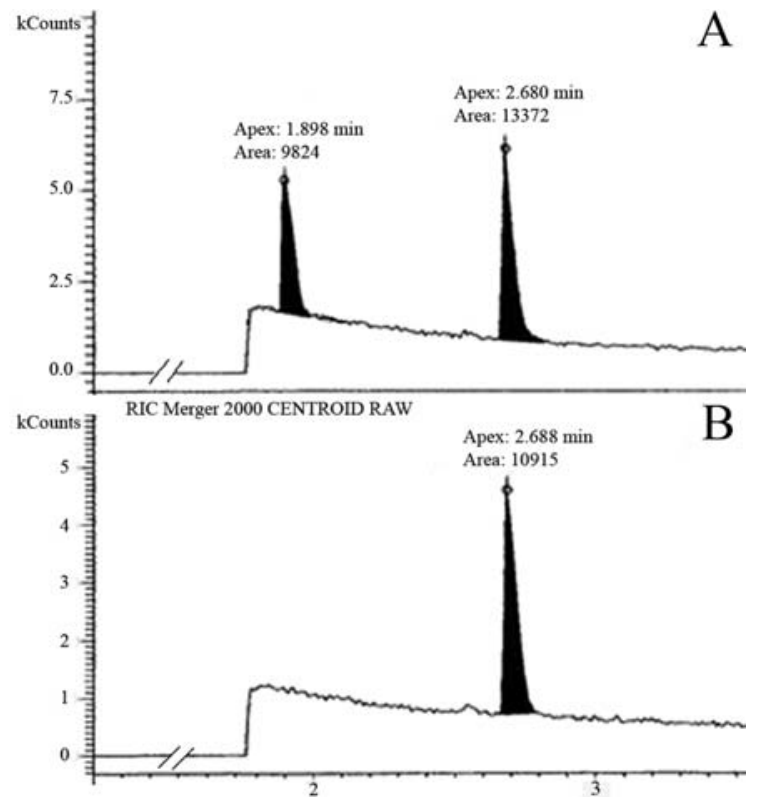

Figure 1. Detection of THF residual solvent within PCL scaffolds by gas chromatography-mass spectrometry (Varian 3800 gas chromatograph and Varian Saturn 2000 ion trap mass detector). (A) Gas chromatogram of a reference THF solution $(0.01 \mathrm{M})$. (B) Gas chromatogram of the third ethanol wash solution used for solvent extraction.

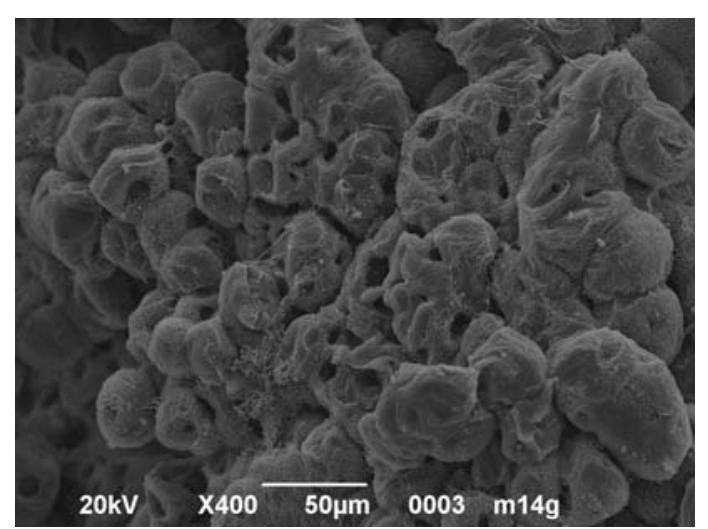

Figure 2. SEM micrograph of PCL scaffolds prepared without a porogen agent. Magnification x400.

while the internal structure of the one obtained using the 30/100 weight ratio demonstrated a higher microporosity grade (Fig. 3B). The total porosity measured was $72 \%$. A more compact structure was observed when the 100/100 weight ratio was used (Fig. 3C).

$P C L-S_{1}$ and $P C L-S_{2}$. When unmicronized sucrose was used as porogen, macropores were detected in the polymeric matrices with a mean dimension nearly the size of the used sucrose particles and appeared to be regularly distributed (Fig. 4A, B, C). Only interconnected trabecular micropores of $<5 \mu \mathrm{m}$ diameter were observed in PCL-S scaffolds obtained with micronized sucrose (Fig. 4D, E, F). A small increase in total porosity (from $75-85 \%$ ) was detected in the scaffolds which was dependent on the increasing sucrose/PCL ratio.
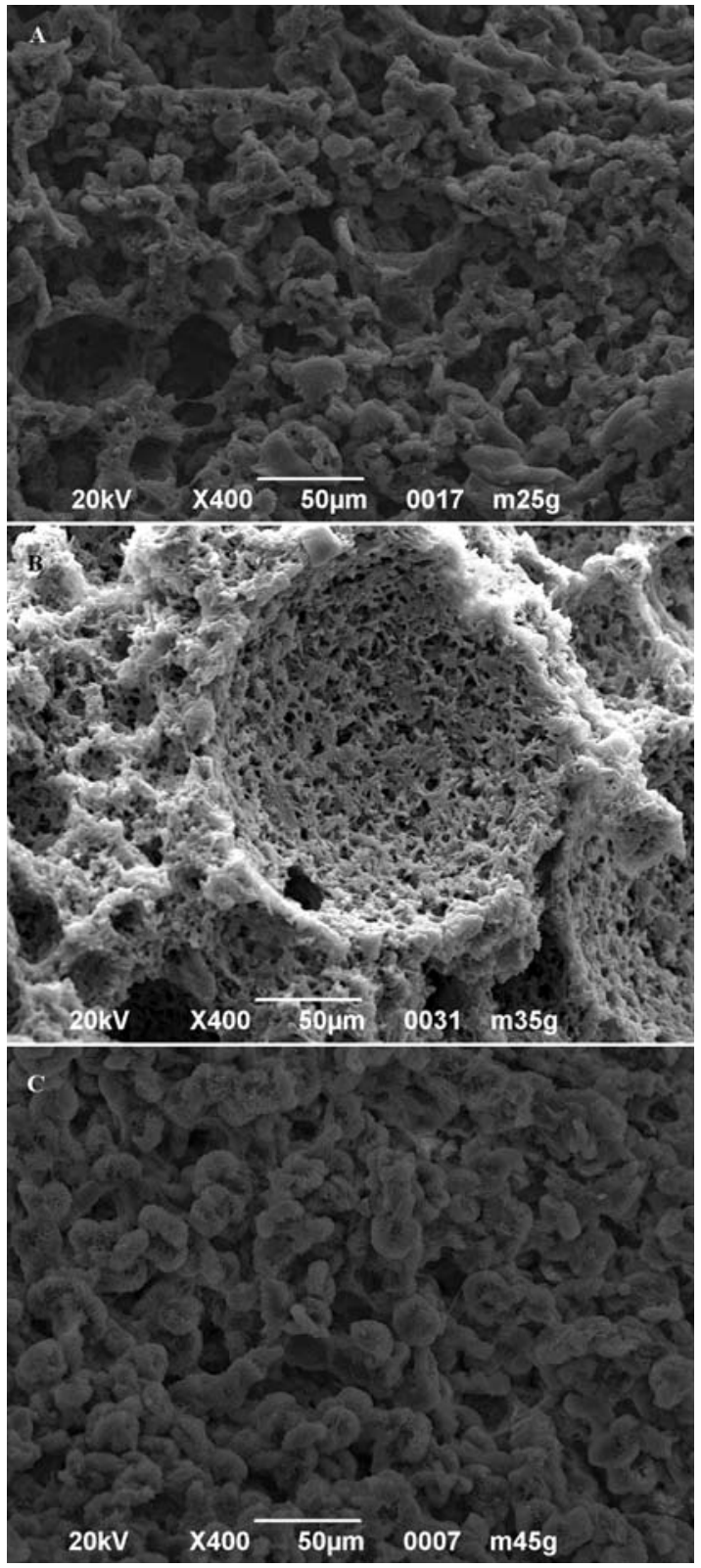

Figure 3. SEM micrographs of PCL scaffolds obtained using polyethylene glycol 1000 (PEG) as a porogen agent. (A) PCL-15\% PEG, (B) PCL-30\% PEG, (C) PCL-100\% PEG. Magnification x400.

$P C L-F$. PCL-F scaffolds were loaded with fructose spheres $(150-400 \mu \mathrm{m})$ as a porogen. PCL-F with a fructose/PCL ratio of 25/100 (Fig. 5A), 50/100 (Fig. 5B), and 100/100 (Fig. 5C) were characterized by the presence of evenly distributed spherical cavities, ranging in size from $\sim 50$ to $200 \mu \mathrm{m}$, within a continuous and microporous PCL matrix. Global porosity was dependent on the fructose loading and was $<80 \%$ in all samples.

PCL-AS and PCL-AT. The PCL-AS (Fig. 6A and B) and PCL-AT (Fig. 6C and D) scaffolds had similar internal structure and morphology. Both PCL scaffolds showed bimodal porosity with large $(50-250 \mu \mathrm{m})$ and small $(5-10 \mu \mathrm{m})$ cavities and total porosity varying between $72-79 \%$. Using calcium alginate as a porogen agent, either in spheres or in threads, we obtained scaffolds with a good porosity and a 

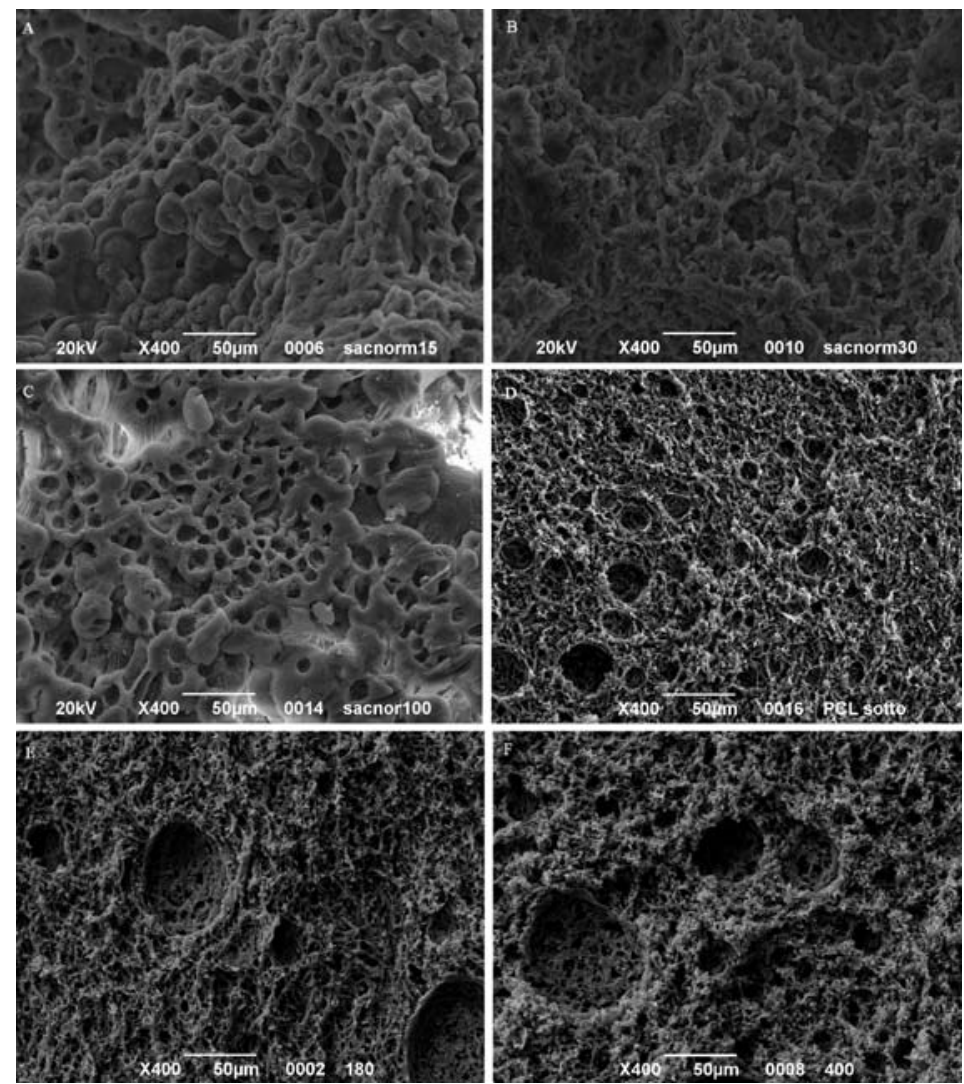

Figure 4. SEM micrographs of PCL scaffolds obtained using unmicronized (A-C) and micronized sieved (D-F) sucrose as a porogen agent. (A) PCL-15\% sucrose, (B) PCL-30\% sucrose, (C) PCL-100\% sucrose, (D) PCL-15\% sucrose (diameter $140 \mu \mathrm{m}$ ), (E) PCL-15\% sucrose (diameter 180 $\mu \mathrm{m}$ ), (F) PCL-100\% sucrose (diameter $400 \mu \mathrm{m}$ ). Magnification $\mathrm{x} 400$.

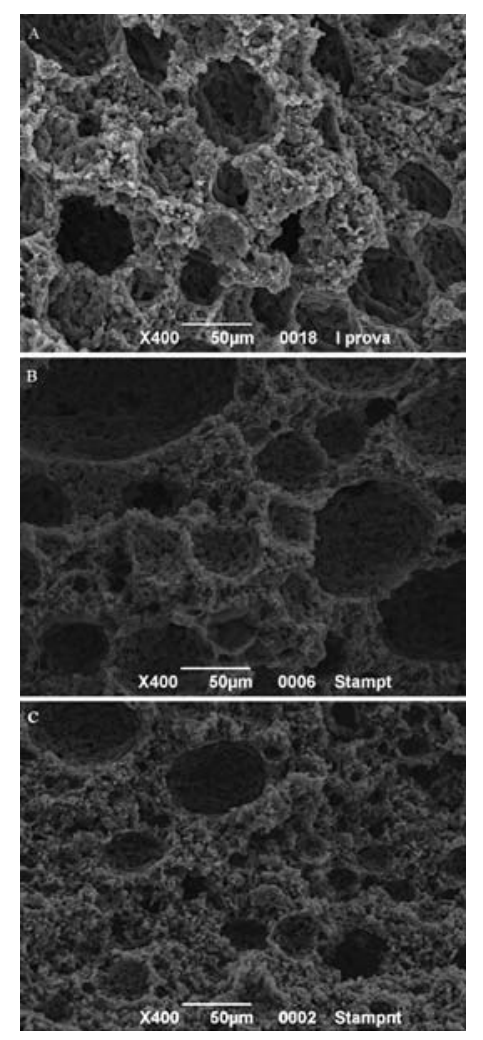

Figure 5. SEM micrographs of PCL scaffolds obtained using fructose spheres (size range, $150-400 \mu \mathrm{m}$ ) as a porogen agent. (A) PCL-25\% fructose spheres, (B) PCL-50\% fructose spheres, (C) PCL-100\% fructose spheres. Magnification x 400 . wide distribution of pore size, which are the two required properties for a bone substitute. Moreover, the scaffolds obtained with $\mathrm{Ca}^{2+}$ alginate threads showed appropriate macropore interconnectivity (Fig. 7B) in comparison to the PCL-AS scaffolds (Fig. 7A). On the basis of this evidence, scaffold characterization by MicroCT analysis and cell viability and biological activity studies were performed only on PCL-AT and PCL-WP scaffolds.

MicroCT. As reported in Table II, porosity and pore diameter ( $\mathrm{Tb} . \mathrm{Sp}$ ) values increased proportionally to the increase in the amount of the porogen $\mathrm{Ca}^{2+}$ alginate threads, in contrast to $\mathrm{BS} / \mathrm{BV}$ and trabecular thickness (Tb.Th) which remained nearly constant. Only the PCL-AT 2 scaffold was characterized by parameters which were all in accordance with those of natural bone and especially in regards to the distribution of pore diameter (Fig. 8) (63). The three-dimensional scaffold reconstruction confirmed the higher number of interconnected pores in PCL-AT 2 (Fig. 9), suggesting a trabecular bone-like framework.

Load-displacement tests (Fig. 10) showed that PCL-AT scaffolds underwent less displacement ( $3 \mathrm{~mm}$ vs. $4.6 \mathrm{~mm}$ for the PCL-AT ${ }_{1}$ and $4.5 \mathrm{~mm}$ for the PCL-WP scaffolds) and showed a lower load of shift/deformation at start $(1.794 \mathrm{~g}$ for the PCL-AT 2 vs. $3.447 \mathrm{~g}$ and $3.200 \mathrm{~g}$ for the PCL-AT ${ }_{1}$ and PCL-WP scaffolds, respectively). On the other hand, the elastic recovery of PCL-AT $2(\sim 2 \mathrm{~mm})$ was higher than that of the PCL-AT $1(1.3 \mathrm{~mm})$ and PCL-WP $(0.6 \mathrm{~mm})$ scaffolds. 

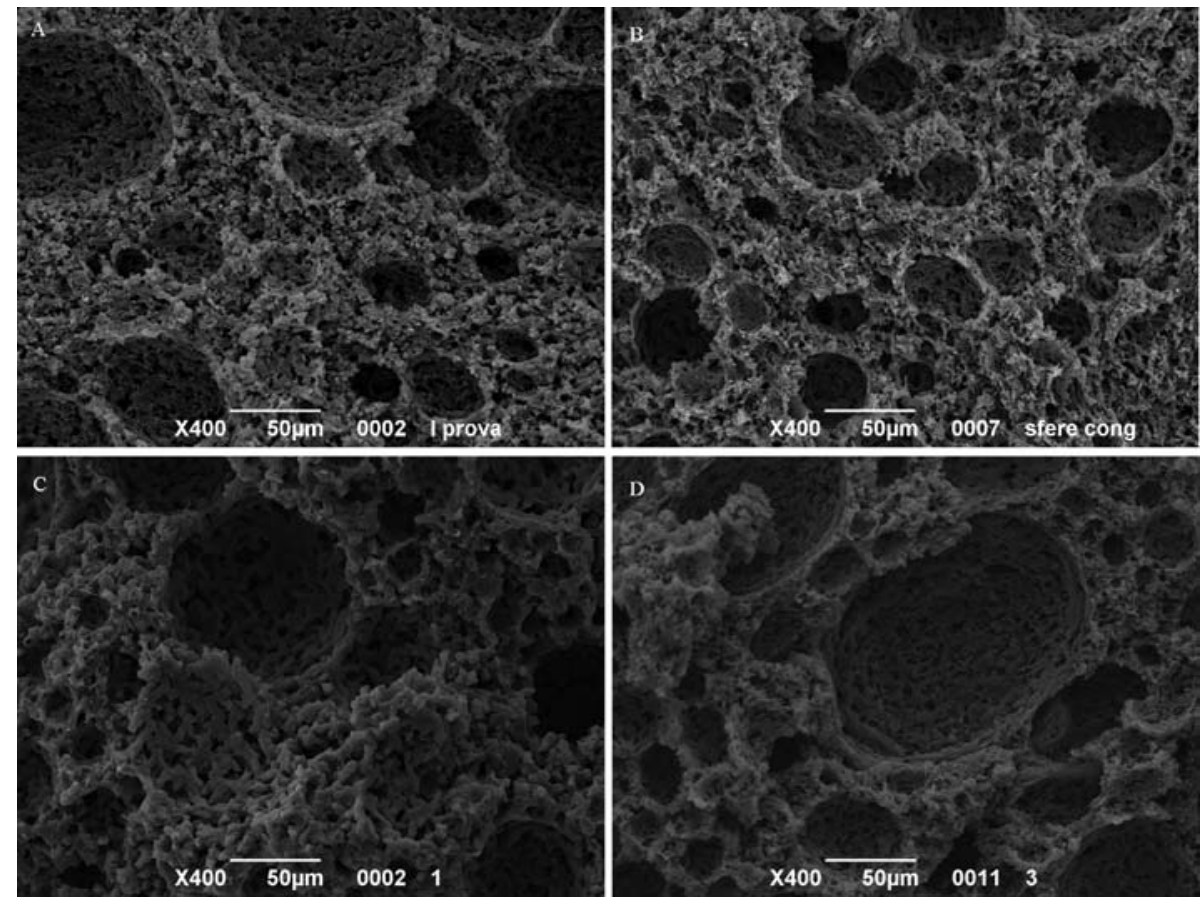

Figure 6. SEM micrographs of PCL scaffolds obtained using $\mathrm{Ca}^{2+}$ alginate spheres (diameter $\left.800 \mu \mathrm{m}\right)(\mathrm{A}, \mathrm{B})$ and $\mathrm{Ca}{ }^{2+}$ alginate threads $(\mathrm{C}$, D) as porogen agents (A) PCL-Ca ${ }^{2+}$ alginate spheres (200/100 ratio), (B) PCL-Ca ${ }^{2+}$ alginate spheres (100/100 ratio), (C) PCL-Ca ${ }^{2+}$ alginate threads (200/100 ratio), (D) PCL-Ca ${ }^{2+}$ alginate threads (100/100 ratio). Magnification x400.

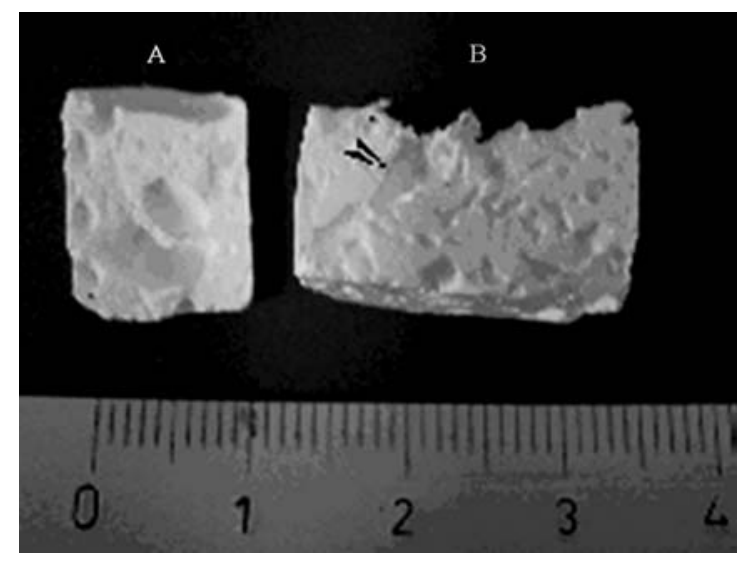

Figure 7. Transversal section of porous PCL scaffolds prepared with $\mathrm{Ca}^{2+}$ alginate spheres (A) and threads (B). More interconnected pores were observed within the PCL Ca ${ }^{2+}$ alginate thread scaffolds.

Modelling PCL replicas of finger phalanx. Using a silicon mould (Fig. 11A) prepared on a model of a human finger phalanx bone, we obtained PCL-WP matrix replicas shaped in a pre-determined form (Fig. 11B). The PCL gel technique approach used herein allowed the construction of PCL scaffolds presenting a volume contraction of about $8 \%$ in respect to the original bone. This effect could be overcome by making a mould slightly larger than the original bone target using a computer-assisted three dimensional modelling and printing. Thus, the replica could be obtained with the exact required dimension. All the external typical characteristics of phalanx bone, as epiphysis and periosteum, were successfully reproduced using the PCL gel technique (Fig. 11C).
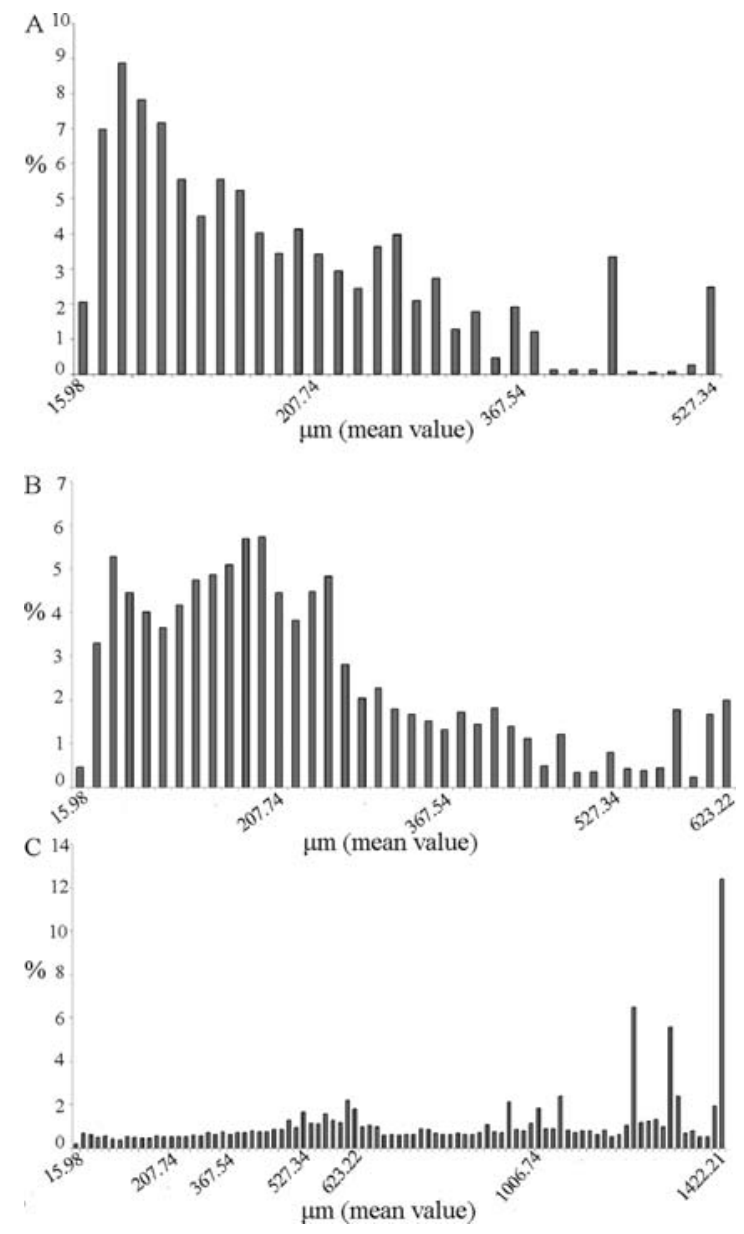

Figure 8. Trabecular separation (Tb.Sp) values measured by MicroCT in PCL scaffolds. (A) PCL-WP; (B) PCL-Ca ${ }^{2+}$ alginate threads (100/100 ratio) (PCL-AT 1 ), (C) PCL- $\mathrm{Ca}^{2+}$ alginate threads (100/200 ratio) $\left(\mathrm{PCL}^{2} \mathrm{AT}_{2}\right)$. 
Table II. MicroCT characterization of PCL-WP and PCL/Ca ${ }^{2+}$ alginate threads scaffolds in comparison to native trabecular bone.

\begin{tabular}{llcrr}
\hline Sample & $\Phi(\%)$ & BS/BV $(1 / \mu \mathrm{m})$ & Tb.Sp mean $(\mu \mathrm{m})$ & Tb.Th mean $(\mu \mathrm{m})$ \\
\hline PCL-WP & $21 \pm 1.52$ & $0.017 \pm 0.0035$ & $172 \pm 6.65$ & $101 \pm 7.75$ \\
PCL-AT $_{1}$ & $52 \pm 2.1$ & $0.024 \pm 0.0037$ & $231 \pm 6.03$ & $91 \pm 3.51$ \\
PCL-AT $_{2}$ & $73 \pm 4.04$ & $0.018 \pm 0.0036$ & $913 \pm 8.88$ & $103 \pm 4.58$ \\
Trabecular Bone $^{\mathrm{a}}$ & $52-96$ & $0.007-0.034$ & $450-1031$ & $80-280$ \\
\hline
\end{tabular}

$\Phi$, total porosity; BS, bone surface; BV, bone volume; TV, total volume; BV/TV, percent of bone volume; Tb.Sp, trabecular separation (pore diameter); Tb.Th, trabecular thickness (pore wall). ${ }^{a}$ Values as reported by Hildebrand et al (63).

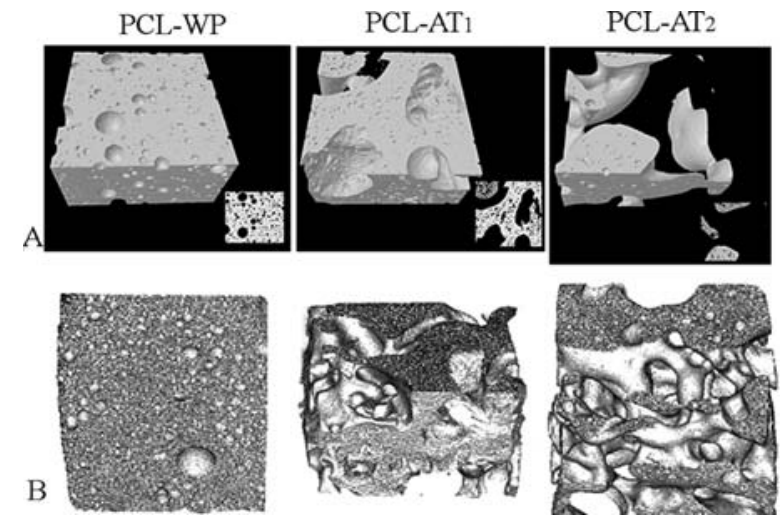

Figure 9. (A) 3D MicroCT isosurface image of PCL scaffolds with various porogen ratios. The insert represents a 2D MicroCT image. (B) 3D image obtained by the Osirix software.

\section{Scaffold biocompatibility}

Cell viability. PCL biocompatibility was evaluated by the MTS assay. Cell viability (expressed as cell number) at $24 \mathrm{~h}$, $72 \mathrm{~h}, 7$ and 14 days after seeding on PCL-WP, PCL-AT 1 and

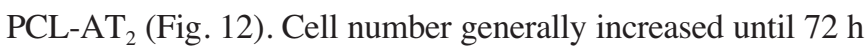
and subsequently decreased in a scaffold-type dependent mode. While no significant difference in cell number was detected between samples at $24 \mathrm{~h}$ and $72 \mathrm{~h}$, a strong decrease in cell viability was observed on the PCL-WP scaffolds at 7 and 14 days. In contrast, PCL-AT $T_{1}$ maintained a good cell viability until 14 days while PCL-AT ${ }_{2}$ showed a statistically significant decrease $(\mathrm{p}<0.05)$ in cell viability at 14 days compared to 7 days.

Cell morphology. SEM micrographs revealed that, after $24 \mathrm{~h}$ incubation time, MC3T3-E1 cells adhered to the polymeric scaffolds (Fig. 13A, B and C) and appeared flattened showing an irregular and elongated form. All polymeric surfaces were completely covered by cells after 7 (Fig 13D, $\mathrm{E}$ and $\mathrm{F}$ ) and 14 days (Fig. 13G, $\mathrm{H}$ and I). Moreover, in the case of PCL scaffolds loaded with alginate threads, cells seemed to grow with a multilayer arrangement.

ALP activity. Low ALP enzyme activity of MC3T3 E1 cells was found in all constructs at 7 days independent of the culture conditions. In contrast, at 14 days the enzyme activity
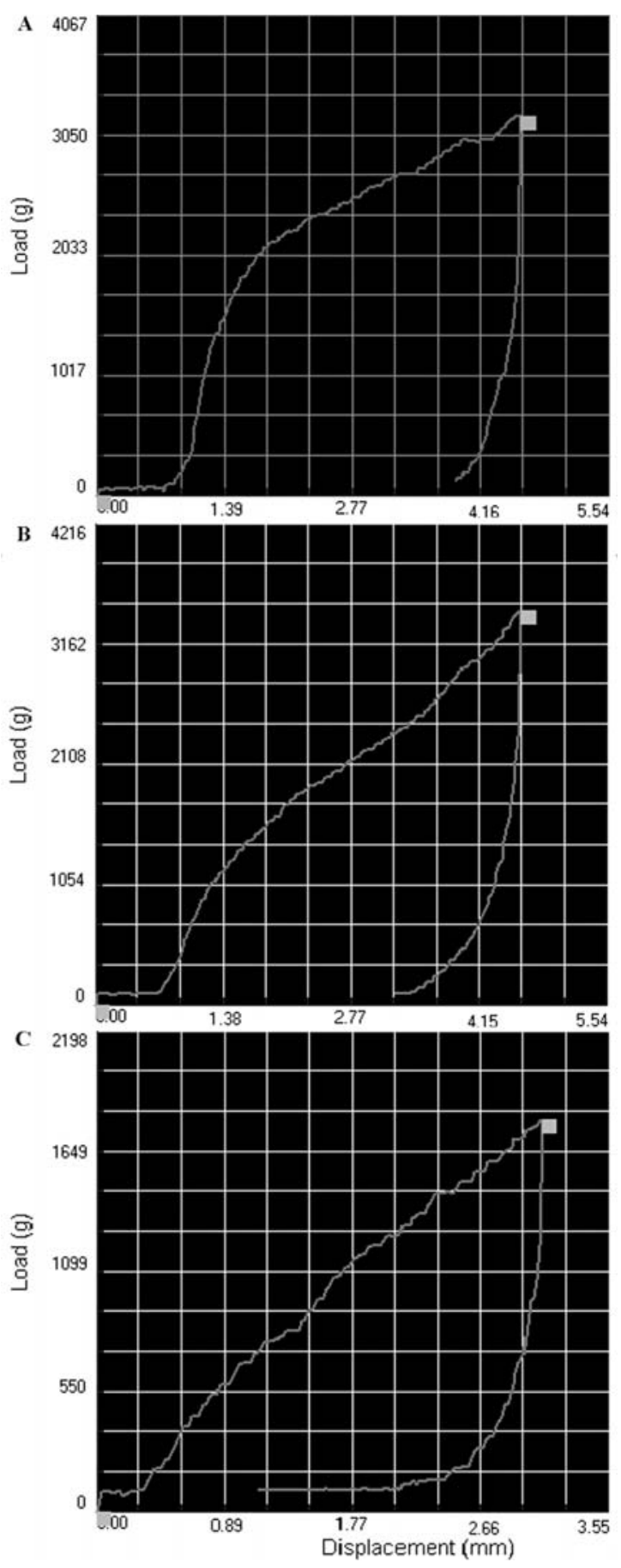

Figure 10. Load-displacement test by MicroCT. (A) PCL-WP, (B) PCL$\mathrm{AT}_{1},(\mathrm{C}) \mathrm{PCL}-\mathrm{AT}_{2}$. 


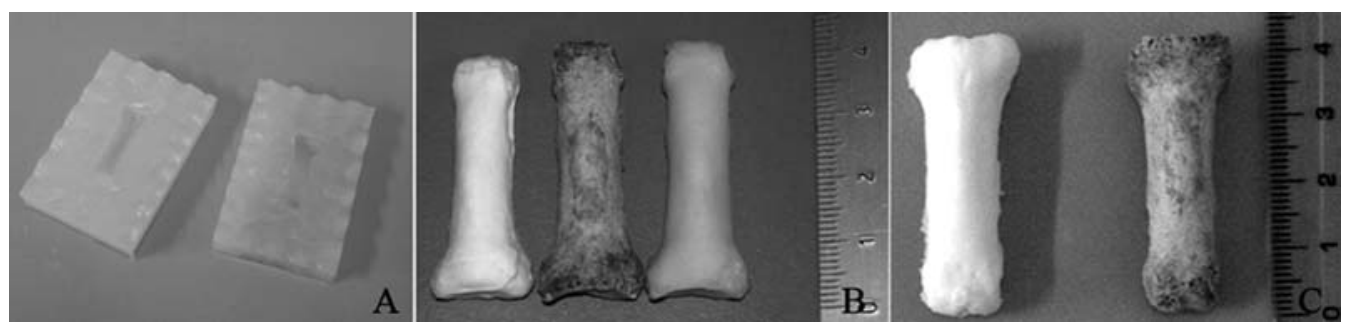

Figure 11. A silicon mould reproducing a human finger phalanx (A) was used to obtain a pre-determined form scaffold. Comparison of human phalanx bone (center) with replicas obtained using PCL (left), or resin (right) (B). Using a mould 8\% larger than the original structure, the size of the PCL phalanx was comparable to the one of native bone.

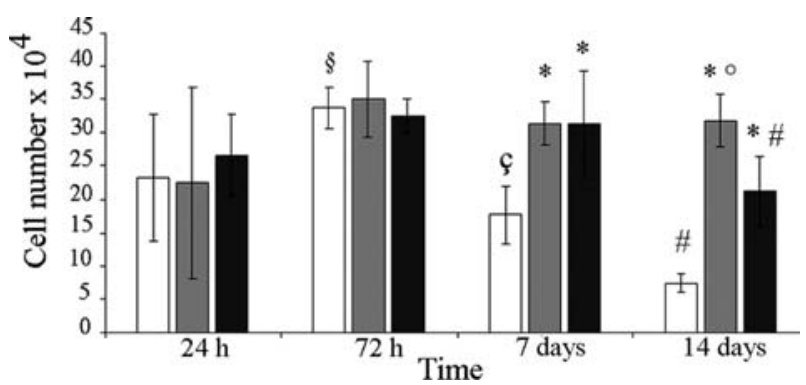

Figure 12. Cell number/cm² of MC3T3-E1 cells on PCL-WP (white), $\mathrm{PCL}^{-\mathrm{AT}_{1} \text { (grey) and PCL-AT }}$ (black) evaluated by the MTS viability assay. The values were obtained from absorbance data of the proliferation assay using a straight calibration line. Data are expressed as the mean $\pm \mathrm{SD}$ of three similar experiments carried out in triplicate mode. Statistical significance: " $\mathrm{p}<0.05$ from PCL-WP; ${ }^{\circ} \mathrm{p}<0.05$ from $\mathrm{PCL}_{-\mathrm{AT}}$; ${ }^{*} \mathrm{p}<0.05$ from same scaffold at $24 \mathrm{~h}, 72 \mathrm{~h}$ and 7 days; ${ }^{\circledR} \mathrm{p}<0.05$ from same scaffold at $24 \mathrm{~h}$, sp $<0.05$ from same scaffold at $72 \mathrm{~h}$.

in osteogenic stimulated and unstimulated PCL-AT $\mathrm{A}_{1}$ and

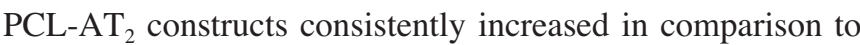
PCL-WP $(\mathrm{p} \leq 0.05)$. Although the ALP activity was significantly decreased in all samples at 21 days of culturing, $\mathrm{PCL}^{-\mathrm{AT}_{2}}$ constructs under osteogenic stimulation conditions showed a significant difference in ALP expression $(\mathrm{p} \leq 0.05)$ in comparison to PCL-WP and PCL-AT 1 (Fig. 14).

In vitro mineralization assay. As shown in Fig. 15, calcium deposits of cells cultured under differentiation conditions were significantly higher in PCL-AT $\mathrm{A}_{1}$ and PCL-AT 2 constructs compared to PCL-WP scaffolds at 14 days, and progressively increased at 21 days of culture. Under basal conditions, cells produced mineralized extracellular matrix at 14 days of culturing in $\mathrm{PCL}_{-} \mathrm{AT}_{2}(\mathrm{p} \leq 0.05)$ and at 21 days in PCL-AT compared to PCL-WP $(\mathrm{p} \leq 0.05)$.

\section{Discussion}

Scaffolds with physical and mechanical properties represent a keystone in tissue engineering to guarantee a structural support for cell adhesion and growth (64). The porosity of bone structures was thoroughly investigated in order to identify a synthetic substitute structure suitable for bone tissue engineering approaches as the appropriate pore size and its distribution facilitate a complete tissue regeneration (65-67). Hildebrand et al (63) reported that the average trabecular thickness of cancellous bone is 100-150 $\mu \mathrm{m}$, while Jowsey (65) calculated the cross-section of Haversian systems to be about 50-250 $\mu \mathrm{m}$ in a human cortical bone. According to Hulbert et al (38), the estimated minimum recommended pore size for a bone scaffold to be $100 \mu \mathrm{m}$. In contrast, further studies have shown that larger pores (diameter, $>300 \mu \mathrm{m}$ ) (68) enhance direct osteogenesis, while smaller ones sustain osteochondral ossification. Although scaffolds with a porosity not less than $70 \%$ and with a pore size between 100-900 $\mu \mathrm{m}$ are commonly proposed for bone tissue engineering applications, the presence of pores with 5-15 $\mu \mathrm{m}$ diameter could be useful to promote neovascularization (69), while pore sizes ranging between $15-50 \mu \mathrm{m}$ permit a proper nutrient diffusion $(38,70)$.

Scaffold mechanical properties for bone regeneration applications are dependent on pore size and other factors including the biomaterial composition and its degradation rate. Scaffolds fabricated from biomaterials with a high degradation rate should not have high porosities (90\%), since its rapid depletion will compromise the mechanical and structural integrity before substitution by the newly formed bone. In contrast, scaffolds produced with biomaterials with low degradation rates and robust mechanical properties can be highly porous, because the higher pore surface area interacting with the host tissue can accelerate degradation due to macrophages via oxidation and/or hydrolysis. To ensure a proper mechanical support as sufficient strength and stiffness in bone regeneration, the scaffold must have an in vivo degradation time of at least 6 months (11).

In this work, the material used, PCL, is a wide-spread biocompatible and biodegradable aliphatic polyester, with a low melting point and good solubility in most solvents $(28,29,33)$. PLC has been approved by the FDA for preparing biomedical devices as urethral catheters, drug delivery systems and resorbable sutures (71), and it has been proposed as a material for tissue engineering of bone and cartilage $(11,20-25)$. Due to its hydrophobic characteristics and semi-crystalline solid phase structure, the entry of biological fluids within PCL scaffolds is hindered and therefore, subsequent chemical degradation is delayed thus, avoiding the local accumulation of toxic substances and the onset of inflammatory processes (20). The long degradation time (12-24 months) of PCL in in vivo settings is a property desirable particularly, for bone substitute prosthesis (28-30).

The purpose of this study was to investigate the phase separation technique in order to obtain a three-dimensional PCL porous scaffold with a structure, porosity and mechanical 

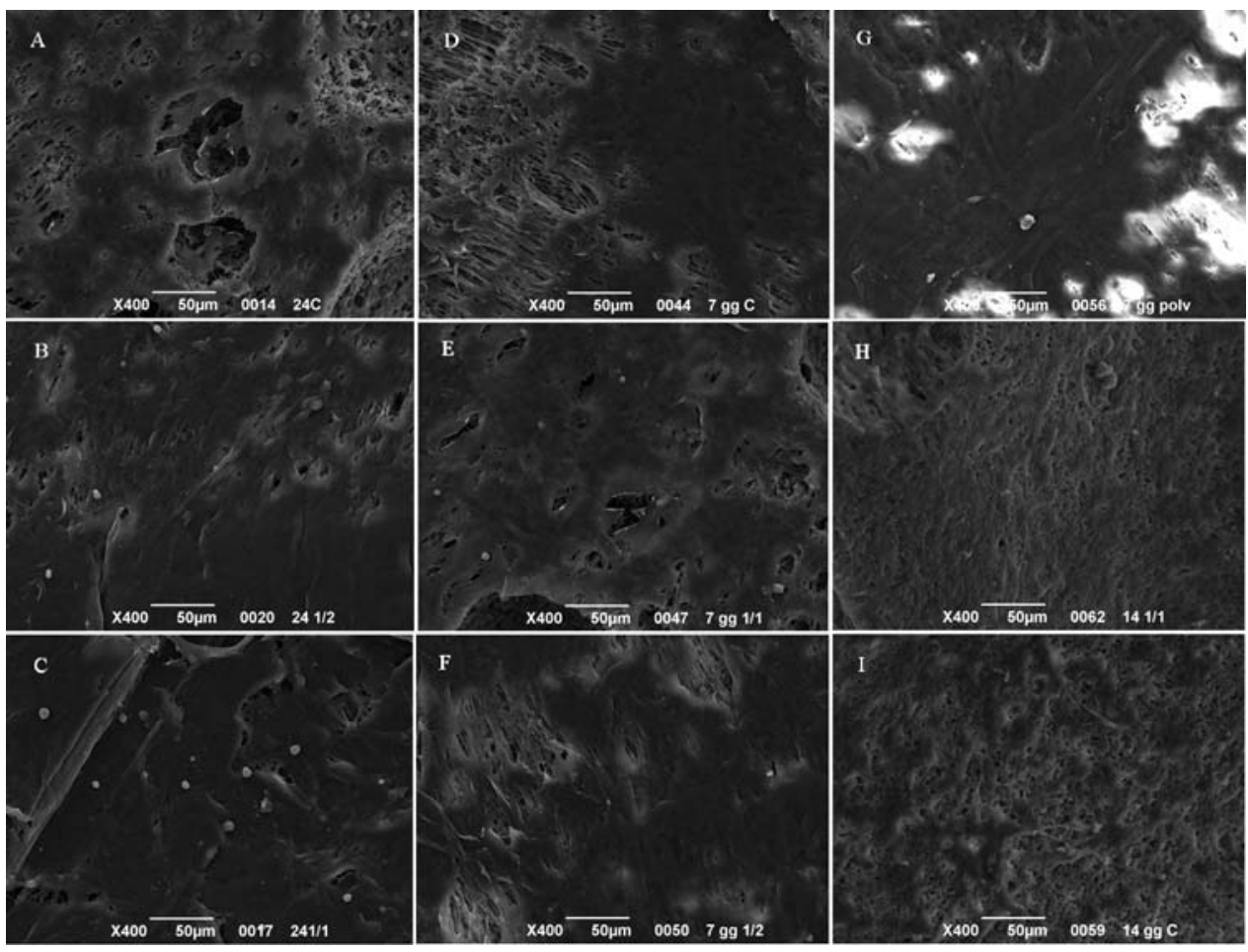

Figure 13. SEM micrographs of MC3T3-E1 osteoblasts on PCL-WP (A, D, G), PCL-AT 1 (B, E, H) and PCL-AT 2 (C, F, I) at incubation time of 24 h (A, B, C), 7 days (D, E, F) and 14 days $(\mathrm{G}, \mathrm{H}, \mathrm{I})$. Magnification $\mathrm{x} 400$.

properties suitable for adhesion, growth, proliferation and differentiation of bone cells. The phase separation technique investigated herein has been proven to be very flexible and useful to prepare scaffolds for bone tissue engineering applications. The polymeric gel obtained can be moulded in any shape and size (52-55). Microporosity of the final object is dependent on the ratio between THF (good solvent for PCL) and water (bad solvent); instead macroporosity is obtained by adding an insoluble material (porogen) with a defined size to the gel phase. The porogen is subsequently removed with an appropriate washing procedure.

The organic solvent THF employed for initial solubilization of PCL is known to be cytotoxic (52) and requires to be removed from scaffolds before cell seeding. Using GC-MS analysis we have demonstrated that after three rinsings with cold ethanol any THF residual was completely removed from the mould.

PCL scaffolds obtained without adding any porogen agent (sample PCL-WP) showed a $70 \%$ porosity when evaluated by density measurement but only a $21 \%$ porosity when using the MicroCT analysis. These conflicting results could be explained by the fact that the SEM analysis of the PCL-WP revealed the presence of micropores with mean dimensions between $5-10 \mu \mathrm{m}$ a range that is clearly below the threshold of the MicroCT instrument. Therefore, the MicroCT analysis in the PCL-WP sample accounted for pores bigger than approximately $10 \mu \mathrm{m}$ which account only for $21 \%$ of the sample volume, while the porosity due to the micropores, accounting for nearly $50 \%$ of the sample volume, was not accounted for by this technique. Using four different porogen agents (PEG 1000, sucrose, fructose and calcium alginate) we have tried to introduce a macroporous structure in PCL scaffolds making them more suitable for application in bone regeneration.

Adding the porogen PEG 1000 we have obtained PCL scaffolds presenting regular pores with size ranging between $10-50 \mu \mathrm{m}$, as observed with SEM. This even pore distribution is, probably, a consequence of the co-solubility of PCL and PEG 1000 in THF.

The removal of porogens like sucrose, fructose and calcium alginate from the gel phase by washings ensures the formation of macropores with a mean dimensional distribution related to the porogen particles size used embedded in a continuous interconnected PCL micropore structure. Regarding sucrose and fructose, the macropores size distribution observed in the final scaffolds always resulted in lower than the initial dimension of porogen added to the gel phase. For example, addition of fructose spheres of 150-400 $\mu \mathrm{m}$ resulted in macropores with a dimension ranging of 50-200 $\mu \mathrm{m}$. This effect could be explained considering the partial solubility of sucrose and fructose in the gel phase containing water.

In this work, the total porosity of all scaffolds were found to be dependent on the PCL:porogen ratio and varied from $72-85 \%$. A biomaterial requirement to guarantee the cell ingrowth is that the interconnected macropores are of appropriate size and geometry. Our MicroCT data showed that only PCL scaffolds obtained using $\mathrm{Ca}^{2+}$ alginate threads fulfill this requiment. The MicroCT analysis revealed that the PCL-AT ${ }_{2}$ scaffold is characterized by morphometric indices (porosity, interconnectivity and distribution of pores values) very similar to those of natural trabecular bone (63). Moreover, as a major surface area stimulates cell attachment and growth (72), PCL-AT were supposed to improve the cellularity in comparison to PCL-WP. The scaffold PCL-AT 2 was shown 

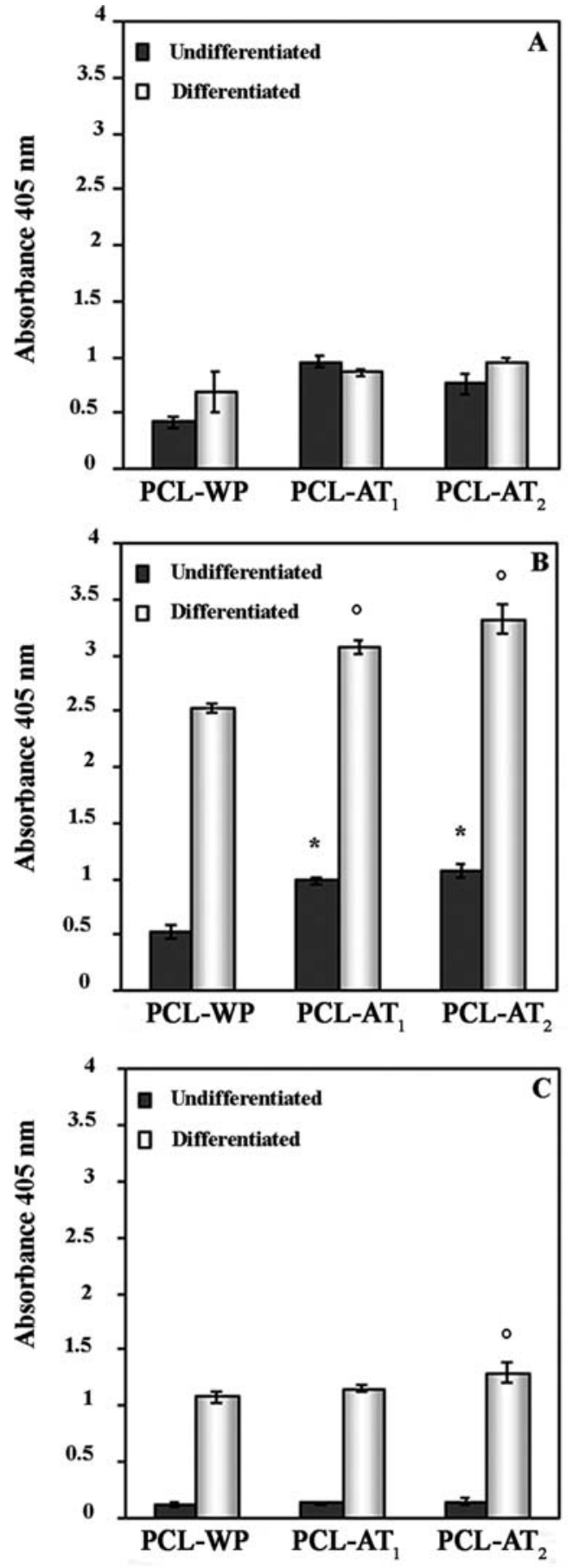

Figure 14. Effects of porosity grade induced by $\mathrm{Ca}^{2+}$ alginate threads on alkaline phosphatase activity in MC3T3-E1 cells at 7 (A), 14 (B) and 21 days (C). Absorbance detection at $405 \mathrm{~nm} .{ }^{*}, \mathrm{p}<0.05$ vs. control.

to possess high elastic recovery, but a low shift/deformation and load-displacement unsuitable for bone substitute applications $(36,73)$. The addition of a mineral component, like hydroxyapatite, to PCL-AT 2 could improve tensile strength and mechanical properties (74).

Biocompatibility analyses (MTS assay and SEM) demonstrated that PCL-AT $\mathrm{A}_{2}$ scaffolds present an environment more suitable for preosteoblastic cell cultures compared to PCL-AT ${ }_{1}$ and PCL-WP. At each evaluation time, the MTS analysis revealed a significant increase in cell growth on $\mathrm{PCL}-\mathrm{AT}_{2}$ compared to PCL-AT 1 and PCL-WP. The interconnected
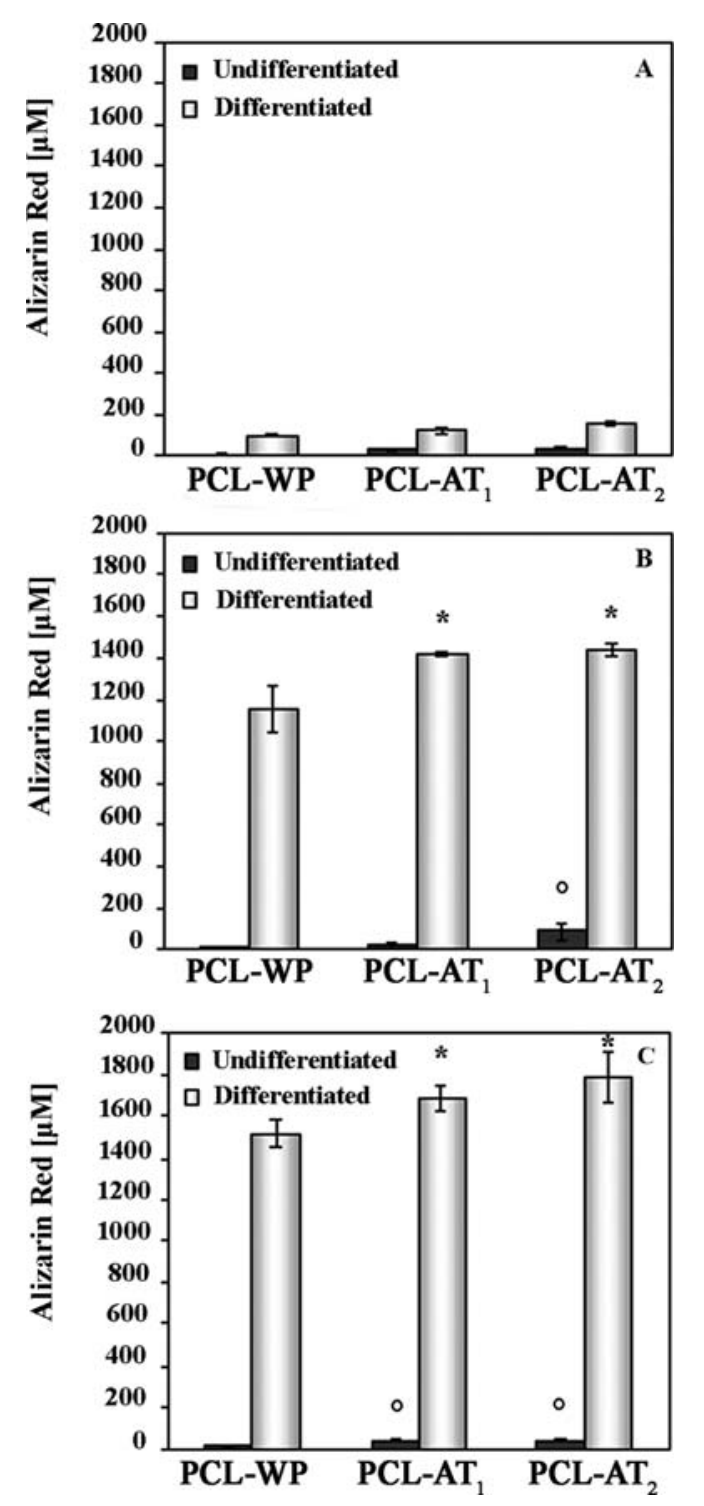

Figure 15. Quantification of calcium deposition by Alizarin Red staining by spectrophotometrical measurement at $562 \mathrm{~nm}$ at 7 (A), 14 (B) and 21 days (C). Values are reported as the mean concentration of Alazarin Red solution extracted from samples of three independent experiments consisting of triplicates. $\stackrel{*}{*} \mathrm{p}<0.05$ vs. control.

pores within the scaffold ensures a major exchange of nutrients and oxygen favoring cell growth and removal of waste products (69-71). The decreased cell number observed after 7 days of culture in PCL scaffolds could be attributed to bone cell cycle properties. Indeed, it has been demonstrated that MC3T3-E1 cells at maximal confluence, reduce the proliferation rate and then start the differentiation process (75).

In this work, using $\mathrm{Ca}^{2+}$ alginate threads as a porogen, we obtained scaffolds of PCL with a porosity grade which met the criterion commonly used to obtain an excellent bone cell ingrowth and differentiation. PCL-AT $\mathrm{A}_{1}$ and PCL-AT $\mathrm{A}_{2}$ were shown to guarantee a better cellular microenvironment and the properly sized interconnected pores seemed to improve the biological properties of PCL scaffolds as demonstrated by the higher ingrowth and responsiveness of MC3T3E1 under basal culture conditions. Furthermore, the total porosity

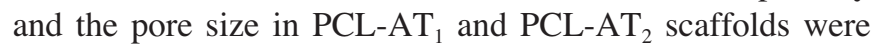


demonstrated to be suitable for sustaining osteogenic differentiation as demonstrated by the increased ALP activity and mineralized extracellular matrix deposition. These results are in accordance with Wang et al (76) that reported that pores with a diameter $>150 \mu \mathrm{m}$ facilitate internal mineralized bone formation.

In conclusion, our results demonstrate that scaffolds prepared with PCL and $\mathrm{Ca}^{2+}$ alginate threads might be considered for bone prosthesis applications as they guarantee a microstructure suitable for bone cell growth and differentiation and ideal porosity grade.

\section{Acknowledgements}

The authors would like to acknowledge Dr Sebastiano Lora (Paleontologic Laboratory-Ca' Foscari University of VeniceItaly) for the photograft and silicon mould of the human finger phalanx, and Saint Luca Hospital-ULSS 18 placed in Trecenta (Rovigo)-Italy for providing laboratory facilities.

\section{References}

1. Ciapetti G, Ambrosio L, Savarino L, Granchi D, Cenni E, Baldini N, Pagani S, Guizzardi S, Causa F and Giunti A: Osteoblast growth and function in porous poly epsiloncaprolactone matrices for bone repair: a preliminary study. Biomaterials 24: 3815-3824, 2003

2. Lin AS, Barrows TH, Cartmell SH and Guldberg RE: Microarchitectural and mechanical characterization of oriented porous polymer scaffolds. Biomaterials 24: 481-489, 2003.

3. Kneser U, Schaefer DJ, Polykandriotis E and Horch RE: Tissue engineering of bone: the reconstructive surgeon's point of view. J Cell Mol Med 10: 7-19, 2006.

4. Banwart JC, Asher MA and Hassanein RS: Iliac crest bone graft harvest donor site morbidity: a statistical evaluation. Spine 20 : 1055-1060, 1995.

5. Goulet JA, Senunas LE, DeSilva GL and Greenfield ML: Autogenous iliac crest bone graft: complications and functional assessment. Clin Orthop Relat Res 339: 76-81, 1997.

6. Parikh SN: Bone graft substitutes: past, present, future. J Postgrad Med 48: 142-148, 2002

7. Datta N, Pham QP, Sharma U, Sikavitsas VI, Jansen JA and Mikos AG: In vitro generated extracellular matrix and fluid shear stress synergistically enhance 3D osteoblastic differentiation. Proc Natl Acad Sci USA 103: 2488-2493, 2006.

8. Lanza RP and Chick WL: Transplantation of encapsulated cells and tissue. Surgery 121: 1-9, 1997.

9. Patrick CW, Mikos AG and McIntire LV: Prospectus of tissue engineering. In: Frontiers in Tissue Engineering. Patrick CW Mikos AG and McIntire LV (eds). Elsevier Ltd., Oxford, pp3-11, 1998.

10. Burg KJL, Porter S and Kellam J: Biomaterial developments for bone tissue engineering. Biomaterials 21: 2347-2359, 2000.

11. Hutmacher DW: Scaffolds in tissue engineering bone and cartilage. Biomaterials 21: 2529-2543, 2000

12. Salgado AJ, Coutinho OP and Reis RL: Bone tissue engineering: state of the art and future trends. Macromol Biosci 4: 743-765, 2004.

13. Stylios G, Wan T and Giannoudis P: Present status and future potential of enhancing bone healing using nanotechnology. Injury 38 (Suppl1): S63-S74, 2007.

14. Spector M: Biomaterials-based tissue engineering and regenerative medicine solutions to musculoskeletal problems. Swiss Med Wkly 136: 293-301, 2006.

15. Kikuchi M, Suetsugu Y and Tanaka J: Preparation and mechanical properties of calcium phosphate/copoly-L-lactide composites. J Mater Sci Mater Med 8: 361-364, 1997.

16. Marra KG, Campbell PG, DiMilla PA, Kumta PN, Mooney MP, Szem JW and Weiss LE: Novel three-dimensional bio-degradable scaffolds for bone tissue engineering. In: Biomedical Materials: Drug Delivery, Implants, and Tissue Engineering. Proceedings of the Materials Research Society Symposium. Nov 5-9, 1999 Vol. 550. Neenan T, Marcolongo M and Valentini RF (eds.). Material Research Society, Boston, pp155-160, 1999.
17. Böstman OM: Absorbable implants for the fixation of fractures. J Bone Surg 73: 148-153, 1991.

18. Bergsma EJ, Bruijn W, Rozema FR, Bos RM and Boering G: Late tissue response to poly(L-lactide) bone plates and screws. Biomaterials 16: 25-31, 1995.

19. Agrawal CM and Athanasiou KA: Techniques to control $\mathrm{pH}$ in the vicinity of biodegrading PLA-PGA implants. J Biomed Mater Res 38: 105-114, 1997.

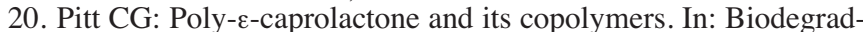
able Polymers as Drug Delivery Systems. Chasin M and Langer R (eds.). Marcel Dekker, New York, pp71-119, 1990.

21. Bezwada RS, Jamiolkowski DD, Lee I, Vishvaroop A, Persivale J, Treka-Benthin S, Erneta M, Suryadevara J, Yang A and Liu S: Monocryl suture, a new ultra-pliable absorbable monofilament suture. Biomaterials 16: 1141-1148, 1995.

22. Benoit MA, Baras B and Gillard J: Preaparation and characterization of protein-loaded poly ( $\varepsilon$-caprolactone) microparticles for oral vecine delivery. Int J Pharm 184: 105-115, 1999.

23. Rohner D, Hutmacher DW, Cheng TK, Oberholzer M and Hammer B: In vivo efficacy of bone-marrow-coated polycaprolactone scaffolds for the reconstruction of orbital defects in the pig. J Biomed Mater Res B Appl Biomater 66: 574-580, 2003.

24. Oh SE, Park IK, Kim JM and Lee JH: In vitro and in vivo characteristics of PCL scaffolds with pore size gradient fabricated by a centrifugation method. Biomaterials 28: 1664-1671, 2007.

25. Ma G, Song C, Sun H, Yang J and Leng X: A biodegradable levonogestrel-releasing implant made of PCL/F68 compound as tested in rats and dogs. Contraception 74: 141-147, 2006.

26. Sung HJ, Carson M, Johnson C and Galis ZS: The effect of scaffold degradation rate on three-dimensional cell growth and angiogenesis. Biomaterials 25: 5735-5742, 2004.

27. Petrie Aronin CE, Cooper JA, Sefcik LS, Tholpady SS, Ogle RC and Botchwey EA: Osteogenic differentiation of dura mater stem cells cultured in vitro on three-dimensional porous scaffolds of poly(epsilon-caprolactone) fabricated via coextrusion and gas foaming. Acta Biomater 4: 1187-1197, 2008.

28. Coombes AGA, Rizzi SC, Williamson M, Barralet JE, Downes S and Wallace WA: Precipitation casting of polycaporlactone for applications in tissue engineering and drug delivery. Biomaterials 25: 315-325, 2003.

29. Ciardelli G, Chiono V, Vozzi G, Pracella M, Ahluwalia A, Barbani N, Cristallini C and Giusti P: Blends of poly $(\varepsilon-$ caprolactone) and polysaccharides in tissue engineering applications. Biomacromolecules 6: 1961-1976, 2005.

30. Kweon HY, Yoo MK, Park IK, Kim TH, Lee HC, Lee HS, Oh JS, Akaike T and Cho CS: A novel degradable polycaprolactone networks for tissue engineering. Biomaterials 24: 801-808, 2003.

31. Causa F, Netti PA, Ambrosio L, Ciapetti G, Baldini N, Pagani S, Martini D and Giunti A: Poly- $\varepsilon$-caprolactone/hydroxyapatite composites for bone regeneration: in vitro characterization and human osteoblast response. J Biomed Mater Res A 76: 151-162, 2005.

32. Lam CX, Hutmacher DW, Schantz JT, Woodruff MA and Teoh SH: Evaluation of polycaprolactone scaffold degradation for 6 month in vitro and in vivo. J Biomed Mater Res 90: 906-919, 2009.

33. Zein I, Hutmacher DW, Tan KC and Teoh SH: Fused deposition modeling of novel scaffolds architectures for tissue engineering applications. Biomaterials 23: 1169-1185, 2002.

34. Kuboki Y, Takita H, Kobayashi D, Tsuruga E, Inoue M, Murata M, Nagai N, Dohi Y and Ohgushi H: BMP-induced osteogenesis on the surface of hydroxyapatite with geometrically feasible and nonfeasible structures: topology of osteogenesis. J Biomed Mater Res 39: 190-199, 1998.

35. Groeneveld EH, van den Bergh JP, Holzmann P, ten Bruggenkate CM, Tuinzing DB and Burger EH: Mineralization processes in demineralized bone matrix grafts in human maxillary sinus floor elevations. J Biomed Mater Res 48: 393-402, 1999.

36. Karageorgiou V and Kaplan D: Porosity of 3D biomaterial scaffolds and osteogenesis. Biomaterials 26: 5474-5491, 2005

37. Story BJ, Wagner WR, Gaisser DM, Cook SD and RustDawicki AM: In vivo performance of a modified CSTi dental implant coating. Int J Oral Maxillofac Implants 13: 749-757, 1998.

38. Hulbert SF, Young FA, Mathews RS, Klawitter JJ, Talbert CD and Steeling FH: Potential of ceramic materials as permanently implantable skeletal prostheses. J Biomed Mater Res 4: 433-456, 1970. 
39. Freed LE, Vunjak-Novakovic G, Biron RJ, Eagles DB, Lesnoj DC, Barlow SK and Langer R: Biodegradable polymer scaffolds for tissue engineering. Biotechnology 12: 689-693, 1994.

40. Mikos AG, Bao Y, Cima LG, Ingber DE, Vacanti JP and Langer R: Preparation of Poly(glycolicacid) bonded fiber structures for cell attachment and transplantation. J Biomed Mater Res 27: 183-189, 1993.

41. Mikos AG, Sarakinos G, Leite SM, Vacanti JP and Langer R: Laminated three dimensional biodegradable foams for use in tissue engineering. Biomaterials 14: 323-330, 1993

42. Mikos AG, Thorsen AJ, Czerwonka LA, Bao Y, Langer R, Winslow DN and Vacanti JP: Preparation and characterization of poly(L-lactic acid) foams. Polymer 35: 1068-1077, 1994.

43. Mooney DJ, Baldwin DF, Suh NP, Vacanti JP and Langer R: Novel approach to fabricate porous sponges of poly(D,L-lacticco-glycolic acid) without the use of organic solvents Biomaterials 17: 1417-1422, 1996.

44. Nam YS, Yoon JJ and Park TG: A novel fabrication method of macroporous biodegradable polymer scaffolds using gas foaming salt as a porogen additive. J Biomed Mater Res 53: 1-7, 2000.

45. Lo H, Ponticiello MS and Leong KW: Fabrication of controlled release biodegradable foams by phase separation. Tissue Eng 1: $15-28,1995$.

46. Lo H, Kadiyala S, Guggino SE and Leong KW: Poly(L-lactic acid) foams with cell seeding and controlled-release capacity. J Biomed Mater Res 30: 475-484, 1996.

47. Schugens C, Maquet V, Grandfils C, Jerome R and Teyssie P: Polylactide macroporous biodegradable implants for cell transplantation II. Preparation of polylactide foams for liquidliquid phase separation. J Biomed Mater Res 30: 449-461, 1996.

48. Nam YS and Park TG: Biodegradable polymeric microcellular foams by modified thermally induced phase separation method. Biomaterials 20: 1783-1790, 1999.

49. Nam YS and Park TG: Porous biodegradable polymeric scaffolds prepared by thermally induced phase separation. J Biomed Mater Res 47: 8-17, 1999

50. Yoshimoto H, Shin YM, Terai H and Vacanti JP: A biodegradable nanofiber scaffold by electrospinning and its potential for bone tissue engineering. Biomaterials 24: 2077-2082, 2003.

51. Jang JH, Castani $\mathrm{O}$ and Kim HW: Electrospun materials as potential platforms for bone tissue engineering. Adv Drug Deliv Rev 61: 1065-1083, 2009.

52. Mikos AG and Temenoff JA: Formation of highly porous biodegradable scaffolds for tissue engineering. EJB Electronic J Biotech 3: 1-6, 2000.

53. Shang M, Matsuyama H, Maki T, Teremoto M and Lloyd DR: Effect of crystallization and liquid-liquid phase separation on phase separation kinetics in poly(ethylene-co-vinyl alcohol)/ glycerol solution. J Polym Sci B Polym Phys 41: 194-201, 2002.

54. Hua FJ, Kim GE, Lee JD, Son YK and Lee DS: Macroporous poly(L-lactide) scaffold 1. Preparation of macroporous scaffold by liquid-liquid phase separation of PLLA-dioxane-water system. J. Biomed Mater Res 63: 161-167, 2002.

55. Shin KC, Kim BS, Kim JH, Park TG, Nam JD and Lee DS: A facile preparation of highly interconnected macroporous PLGA scaffolds by liquid-liquid phase saparation II. Polymer 46: 3801-3808, 2005.

56. Wei G and Ma PX: Macroporous and nanofibrous polymer scaffolds and polymer/bone-like apatite composite scaffolds generated by sugar spheres. J Biomed Mater Res A 78: 306-315 2006.

57. Smidsrød O and Skjåk-Bræk G: Alginate as immobilization matrix for cells. Trends Biotechnol 8: 71-78, 1990

58. Oh SH, Kang SG, Kim ES, Cho SH and Lee JH: Fabrication and characterization of hydrophilic poly(lactic-co-glycolic acid)/poly(vinyl alcohol) blend cell scaffolds by melt-molding particulate-leaching method. Biomaterials 24: 4011-4021, 2003.
59. Lewandrowski KU, Hile DD, Thompson BM, Wise DL, Tomford WW and Trantolo DJ: Quantitative measures of osteoinductivity of a porous poly(propylene fumarate) bone graft extender. Tissue Eng 9: 85-93, 2003.

60. Kim HW, Knowles JC and Kim HE: Hydroxyapatite/ poly(epsilon caprolactone) composite coatings on hydroxyapatite porous bone scaffold for drug delivery. Biomaterials 25 : 1279-1287, 2004.

61. Leon y Leon CA: New perspectives in mercury porosimetry. Adv Colloid Interface Sci 76-77: 341-372, 1998.

62. Cartmell S, Huynh K, Lin A, Nagaraja S and Guldberg R: Quantitative microcomputed tomography analysis of mineralization within three-dimensional scaffolds in vitro. J Biomed Mater Res A 69: 97-104, 2004

63. Hildebrand T, Laib A, Müller R, Dequeker J and Rüegsegger P: Direct three-dimensional morphometric analysis of human cancellous bone: Microstructural data from spine, femur, iliac crest, and calcaneus. J Bone Miner Res 14: 1167-1174, 1999.

64. Ma PX: Scaffolds for tissue fabrication. Materials Today 7: 30-40, 2004.

65. Jowsey J: Studies of haversian systems in man and some animals. J Anat 100: 857-864, 1966.

66. Lanza RP, Langer R and Vacanti J: Principles of Tissue Engineering. Academic Press, San Diego, 2000.

67. Lebourg M, Sabater Serra R, Mas Estelles J, Hernandez Sanches F, Gomez Ribelles JL and Suay Anton J: Biodegradable polycaprolactone scaffold with controlled porosity obtainedby modified particle-leaching tecnique. J Mater Sci Mater Med 19: 2047-2053, 2008.

68. Kuboki Y, Jin Q and Takita H: Geometry of carriers controlling phenotypic expression in BMP-induced osteogenesis and chondrogenesis. J Bone Joint Surg Am 83-A (Suppl. 1): S105-S1 15, 2001.

69. Klawitter JJ and Hulbert SF: Application of porous ceramics for attachment of load bearing internal orthopedic applications. J Biomed Mater Res 5: 161-229, 1971

70. Cerroni L, Filocamo R, Fabbri M, Piconi C, Caropeso S and Condò SG: Growth of osteoblast-like cells on porous hydroxyapatite ceramics: an in vitro study. Biomol Eng 19: 119-124, 2002.

71. Domb AJ, Kost J and Wiseman DM: Handbook of Biodegradable Polymers. Harwood Academic Publishers, Amsterdam, 1997

72. Yang S, Leong KF, Du Z and Chua CK: The design of scaffolds for use in tissue engineering. Part I. Traditional factors. Tissue Eng 7: 679-689, 2001.

73. Currey JD: Mechanical properties of vertebrate hard tissues. Proc. Inst Mech Eng H 212: 399-411, 1998.

74. Yu H, Matthew HW, Wooley PH and Yang SY: Effect of porosity and pore size on microstructures and mechanical properties of poly- $\varepsilon$-caprolactone-hydroxyapatite composites. J Biomed Mater Res B Appl Biomater 86: 541-547, 2008.

75. Choi JY, Lee BH, Song KB, Park RW, Kim IS, Sohn KY, Jo JS and Ryoo HM: Expression patterns of bone-related proteins during osteoblastic differentiation in MC3T3-E1 cells. J Cell Biochem 61: 609-618, 1996

76. Wang H, Li Y, Zuo Y, Li J, Ma S and Cheng L: Biocompatibility and osteogenesis of biomimetic nano-hydroxyapatite/polyamide composite scaffolds for bone tissue engineering. Biomaterials 28: 3338-3348, 2007. 